The serological investigations had been greatly complicated by a lack of knowledge of the blood groups of horses and by difficulty in obtaining blood samples from the sires of the affected foals. However, they had tested the sera of all the mares, the offspring of which were affected, against the red cells of other mares and of various other available horses. They had found that most of the sera contained high titre saline agglutinins acting on various other horse bloods and all contained blocking antibodies, revealed by the indirect antiglobulin sensitization test. None of the control sera contained more than traces of iso-antibodies.

As in the human disease, the direct anti-globulin sensitization test had proved extremely valuable in making a rapid diagnosis. Hæmolytic disease in new. born foals had to be differentiated from bacterial septicæmia which might also cause jaundice. They had tested six cases of hæmolytic disease, all of which had given strongly positive tests, and two cases of septicæmia, both of which had given negative tests. The reagent they had used was a rabbit anti-horse globulin serum.

The hæmatological picture was one of profound anæmia, with hæmoglobin levels of only 3-4 gm. per $100 \mathrm{ml}$. Nevertheless, very few reticulocytes and no erythroblasts were seen in the peripheral blood.

One of the most interesting features of the morbid histology was an extension of tubular epithelium into the glomeruli in three cases which had shown hæmoglobinuria; similar changes had been observed in 'traumatic anuria' in man.

Finally, Dr. Coombs mentioned some work which Dr. Heard is conducting. This is an attempt to produce hæmolytic disease in rabbits. There was every reason for hoping that this work would be successful and there was no need to stress the advantage that would result from having a laboratory animal in which the disease could be produced at will. Many problems of hæmolytic disease could only be investigated by experiment and could therefore never be tackled directly in man.

P. L. MOLIISON

\section{GENETICAL STRUCTURE OF PLANT POPULATIONS}

A

SYMPOSIUM on the "Genetical Structure of Plant Populations" was held at the Brighton meeting of the British Association for the Advancement of Science, on September 13, in Section $K$ (Botany), with Col. F. C. Stern in the chair. Dr. W. B. Turrill (Kew), in an opening paper, defined a population, as the term should be used in biology, as the sum total of individuals of a stated kind, in a stated area, at a stated time. The need of careful determination of 'kind' and the desirability of preserving proper voucher specimens where there is the slightest possibility of determinations being called in question were emphasized. The extensive and intensive studies now being completed on numerous populations of a limited number of species of seedbearing plants of the European flora have revealed an unexpected wealth of variation in structure and behaviour. At Kew and Potterne, investigations combining the methods of modern taxonomy, cytogenetics and ecology are throwing much light upon the make-up of species as population complexes. Attention was directed to the bladder campions
(Silene maritima and allied species). In these some variations are common, as degrees of indumentum in $S$. cucubalus, others are rare, as long cylindrical calyx in $S$. maritima. Some characters have obvious survival value for definite ecological habitats, such as habit differences between different species or varieties. Spasmodically occurring mutations may be lethal or harmful in various degrees, like 'poor petal' or 'split calyx', whereas other variations appear to be neutral at least in some environments. Some variants have a wide geographical range while others are restricted to very local habitats. Hybridization experiments on a very extensive scale have shown genetic differences for most of the variations; but whereas some characters have a simple genetic basis others can only be explained by the interaction of several genes. Long-isolated populations of relatively small size (as some inland populations of $S$. maritima) may show much less variation than is normally found in more widely spread populations. Parallelism between sea-coast and high-mountain populations of different species is very striking.

Mr. J. L. Crosby (Durham) dealt with intrapopulation heterogeneity and the breeding range of the individual plant. In the primrose (Primula vulgaris), in addition to reciprocally outcrossing plants with 'pin' and 'thrum' flowers, there are, in certain populations in Somerset and the Chilterns, plants with 'long homostylous' flowers which are normally self-fertilized and outcross on to pins. Observation agrees with theoretical conclusions that 'homostyles' are increasing to about 80 per cent, 'pins' are decreasing to about 20 per cent, and 'thrums' are entirely disappearing. Slow at first, change later becomes quite rapid. Considerable heterogeneity between different parts of any one such population may exist. A few yards only may separate groups with constitutions so different that they represent evolutionary stages many generations apart. Such large differences cannot have arisen in one generation by chance from a homogeneous population but must have been initiated at an early stage. One section of the population reached the stage of more rapid change and the difference then became amplified. The change could not, however, even be maintained with free distribution of pollen between the divergent groups, even though 'homostyles' are self-pollinated. The breeding range of the individual primrose must be of the order of a few yards only, and a single population cannot be considered as a continuous interbreeding unit.

Dr. A. J. Bateman (John Innes Institution) considered populations of cultivated plants. He pointed out that the breeding system of the species is of paramount importance in determining the genetical structure of a population. The total range of breeding systems is from complete self-fertilization as in barley to complete cross-fertilization as in cabbage. Subordinated to the breeding system are selection intensity, population size, and gene dispersal. Heritable variation would be at a minimum in a pure line; but varieties of self-fertilizing crops are rarely represented by pure lines. The different causes of variation within varieties which should be pure lines are: (a) residual hybridity of the original variety; (b) mutation and structural change; (c) seed admixture; (d) cross-pollination. Cultivated plants show a continuous range in breeding systems from self-incompatibility and diœcism giving full outbreeding, to regular self-pollination and vegetative reproduction, giving full inbreeding or its equivalent. 
Experiments with rye indicate that thirty-six plants can maintain a variety in its original form; but six plants are too few to avoid inbreeding depression and undesirable loss of variability in cross-breeding crops. Cultivated plants are selected for a special environment. When human selection is relaxed the subsequent deterioration shows us how natural populations with similar breeding systems will respond to changes of environment. A study of the dispersal of pollen of cultivated plants shows that inter-crossing is mainly confined to immediate neighbours, though finite amounts of crossing occur up to large distances. The part which this dispersal plays in determining population structure again depends on the breeding system.

Dr. H. G. Baker gave an account of gene-flow between inter-fertile species. In 'pauciform' hybrids, the individuals are without fertility and cannot be back-crossed to their parents or form segregating swarms by selfing. Other hybrids, termed 'multiform', are sufficiently fertile to perform either of, or both, these acts. Yet in 'multiform' hybrids gene-flow is often restricted or even absent. In the sub-tribe Madiinæ of Compositæ, lack of intermal harmony within the plant may lead to certain 'recombination types' failing to endure serious competition. Selfpollination reduces frequency of hybrids, as do also cleistogamy as in Viola and apomixis as in Poa. Certation effects favouring pollen-tubes of the same species as the styles also reduce interspecific hybrids as in Melandrium. Interspecific hybridization is more likely to occur where one or both species is underrather than over-dispersed. Matrocliny may increase the possibility of gene-flow. Linkage hinders generecombination and may be of importance in preserving the parental types in natural populations. "Variance of fertility' is sometimes seasonal. Internally determined restrictions on gene-flow are no less important than those imposed by the external environment. Some hybrid swarms develop under man's influence; others do not. When two kinds of plants come to occupy adjacent habitats, the exchange may occur of genes resulting in characters which are neutral so far as the ecological distinction between the kinds is concerned. With modification of the environment, characters excluded previously on ecological grounds may occur.

Dr. D. H. Valentine described interspecific hybridization between primrose (Primula vulgaris) and oxlip $(P$. elatior) in woods in certain regions of East Anglia. The populations of individual woods are isolated from one another. Some woods contain one or other of the pure species, others contain the two species and their hybrids. Where the species meet, they occupy distinct areas in the wood, probably because of their different ecological preferences. Hybrids are always frequent, but they do not outnumber the pure species. From reciprocal artificial crosses, a low yield of viable seeds is obtained, and the vigour of the $F_{1}$ hybrids is variable. A somewhat better yield of seed is obtained when the $F_{1}$ hybrid is selfed or backcrossed. There are thus both ecological and genetical barriers which tend to prevent fusion of the species. The condition appears to be one of equilibrium, which may shift in one direction or the other as variations of local climate and other environmental factors occur. Efficient barriers of more than one kind separate oxlip and cowslip ( $P$. veris), and the hybrid between primrose and cowslip, which is partially fertile, is of widespread occurrence; but extensive hybrid populations are apparently rare, perhaps because of the marked ecological differences between the species.

In the discussion following the five papers, Dr. J. M. Rasmusson commented upon the successful attempt to combine the points of view of wild and cultivated plants, of the botanist and the plantbreeder. In sugar-beet it had been found that from five to ten plants were too few and forty to sixty plants enough to prevent inbreeding depression. A distance of 200 yards prevents crossing in the open in sugar-beet. Dr. C. D. Darlington questioned Mr. Crosby's explanation of the spread of homostylous plants in his primrose populations. Prof. J. G. Nannfeldt urged that the experimental methods of genetics and ecology should be increasingly applied to the native flora. Captain C. D. Diver noted that while there were considerable differences in breeding mechanisms between animals and plants, results were often similar. Mr. A. J. Wilmott asked that more investigation should be undertaken on chances of cross-pollination by wind with increasing distance. Mr. O. H. Frankel maintained that seed merchants in Great Britain aimed for saleability (largely a matter of uniformity), not quality (productivity).

\section{APPLICATION OF OXYGEN TO STEEL-MAKING}

\author{
BY DR. W. C. NEWELL \\ British Iron and Steel Research Association
}

$M$ ANY modern technical developments have been made by preparing materials of greater suit. ability for specific purposes from the naturally occurring materials which were employed earlier. An obvious example of this is seen in the superior materials now used for building construction and a comparison with natural clay which is still used in some places. Though air has, wittingly or unwittingly, been used for combustion from very early times, the bulk manipulation of gases on a commercial scale is such a modern development that the commercial use of oxygen for combustion is only now just becoming possible. The use of an oxygen-enriched air blast does not appreciably increase the heat of combustion, but it does reduce the cooling effect of the nitrogen present in air which is normally passed through furnaces. The magnitude of this effect is appreciated when it is pointed out that during the combustion of carbon to the dioxide with ordinary air, the weight of nitrogen involved is nearly ten times the weight of the carbon. Under certain conditions thermal recuperation or regeneration of the heat from the gases leaving the furnace is possible, but at high temperatures this is inefficient and costly.

The magnitude of the loss of sensible heat with the nitrogen passing off from furnaces is greater the higher the temperature, and for steel-making temperatures, of say up to $1,700^{\circ} \mathrm{C}$., it becomes of such major importance that many attempts have been made in various parts of the world to employ oxygen. enrichment to improve the thermal efficiency of steel-making processes. Recently ${ }^{1}$ full technical details have been published of the way in which oxygen-enrichment is being successfully applied on a continuous production basis at Messrs. Cattons' steel foundry in Leeds. The accompanying chart shows for the combustion of carbon to dioxide the number of 